\title{
GLOBAL CONSUMER CULTURE AND LOCAL IDENTITY AS DRIVERS OF MATERIALISM: AN INTERNATIONAL STUDY OF CONVERGENCE AND DIVERGENCE
}

\author{
Mark Cleveland, University of Western Ontario, Canada \\ Michel Laroche, Concordia University, Canada \\ Nicolas Papadopoulos, Carleton University, Canada
}

\begin{abstract}
Globalization profoundly affects societies and individual consumers. Materialism is presumed to be a core characteristic of global consumer culture. Consumption-related values like materialism are pertinent for understanding the establishment, maintenance, and expression of cultural identity in the era of globalization. Worldwide, advertisers employ numerous themes associated with materialism: luxury, success, accumulation, happiness, glamour, and exclusivity, which serve to reinforce status, social class and the desirability of upward social mobility. Whereas much scholarly work has attended to materialism, cross-cultural studies examining its drivers are relatively scarce, inhibiting theory generalization to international contexts.

To what extend does globalization promote the diffusion of a materialistic global consumer culture? Are national and ethnic cultures revitalizing in the face globalization and if so, is there any evidence that nationalistic and parochially-inclined consumers are resisting materialistic tendencies? More specifically, how and to what degree do the facets of global consumer culture and ethnic affiliation drive materialism, and how uniform are these relationships across countries and cultures? This question is probed with survey data drawn from more than 2000 consumers living in eight countries, drawn from North and South America, Western and Eastern Europe, as well as South and East Asia. Likert and semantic differential scales included multidimensional measures for ethnic identity (43 items) acculturation to global consumer culture (65 items), materialism (9 items), consumer ethnocentrism (4 items), as well as numerous socio-demographic indicators. Three levels of analyses (within-, between-, and across- country samples) were conducted, consisting of factor, reliability and correlational analyses; as well as multivariate analyses of covariance.

Robust support emerged for the proposition that acculturation to global consumer culture drives materialistic values. Whereas most constituent dimensions associate with increasing levels of materialism, merely speaking more English does not, by itself, promote materialism. Rather, materialistic dispositions are shaped by intensive exposure to the marketing activities of multinational firms, via global (particularly, American) mass media, and also, by first-hand intercultural encounters. Possessions and luxury are important to the global consumer, and $\mathrm{s} / \mathrm{he}$ is indifferent as to whether these material goods are produced locally or abroad, as evidenced by the lack of association between consumer ethnocentrism and materialism. Although mixed results were evidenced for the relationship of materialism to ethnic identity facets, the bulk of the significant relationships were positive, demonstrating that cultural traditions are not incompatible with materialistic tendencies, particularly with respect to interpersonal relationships with fellow ethnic members. Other similarities and differences are reported. Overall, the results underscore the notion that identity positions are fluid and in motion, as the result of reconciling the various acculturation factors facing individuals under different contexts. The results further suggest that materialism is inherent as well as learnable. Segments spill over national boundaries, and therefore, it is imperative to identify conditions under which consumer commonalities and dissimilarities are most likely to emerge.
\end{abstract}

References available upon request. 